\title{
Differences and Similarities in the Peptide Profile of Preterm and Term Mother's Milk, and Preterm and Term Infant Gastric Samples
}

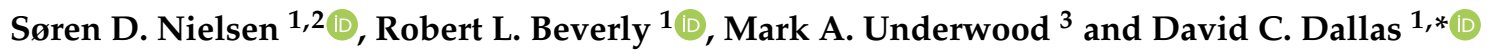 \\ 1 Nutrition Program, School of Biological and Population Health Sciences, College of Public Health and \\ Human Sciences, Oregon State University, Corvallis, OR 97331, USA; sodn@food.au.dk (S.D.N.); \\ beverlyr@oregonstate.edu (R.L.B.) \\ Department of Food Science, Faculty of Technical Sciences, Aarhus University, 8200 Aarhus, Denmark \\ 3 Department of Pediatrics, University of California, Sacramento, CA 95817, USA; munderwood@ucdavis.edu \\ * Correspondence: Dave.Dallas@oregonstate.edu; Tel.: +1-541-737-1751
}

Received: 23 July 2020; Accepted: 10 September 2020; Published: 15 September 2020

\begin{abstract}
Our previous studies revealed that milk proteases begin to hydrolyze proteins in the mammary gland and that proteolytic digestion continues within the infant stomach. No research has measured how the release of milk peptides differs between the gastric aspirates of term and premature infants. This study examined the presence of milk peptides in milk and gastric samples from term and preterm infants using an Orbitrap Fusion Lumos mass spectrometer. Samples were collected from nine preterm-delivering and four term-delivering mother-infant pairs. Our study reveals an increased count and ion abundance of peptides and decreased peptide length from mother's milk to the infant stomach, confirming that additional break-down of the milk proteins occurred in both preterm and term infants' stomachs. Protein digestion occurred at a higher level in the gastric contents of term infants than in gastric contents of preterm infants. An amino acid cleavage site-based enzyme analysis suggested that the observed higher proteolysis in the term infants was due to higher pepsin/cathepsin D activity in the stomach. Additionally, there was a higher quantity of antimicrobial peptides in term infant gastric contents than in those of preterm infants, which could indicate that preterm infants benefit less from bioactive peptides in the gut.
\end{abstract}

Keywords: premature infant; term infant; peptidomics; nutrition; human milk; bioactive

\section{Introduction}

Preterm birth, defined as birth prior to 37 weeks of gestational age (GA), occurs in nearly one in every ten births in the United States [1]. Despite advances in medicine that have increased the survival of preterm infants in recent decades, these infants remain at increased risk for morbidities related to underdevelopment compared with their term counterparts [2,3].

Preterm infants have underdeveloped gastrointestinal (GI) systems that may impede their ability to adequately break down the complex macronutrients provided by mother's milk, which could be partially responsible for their increased risk of growth inadequacy and developmental issues. At birth, the means by which these infants acquire nutrients shifts from the direct supply of sugars, amino acids, and free fatty acids via the mother's placenta to ingestion of milk's carbohydrates, lipids, and proteins, which must be digested and absorbed. Protein digestion in the stomach is initiated by the secretion of gastric acid and pepsin, which denature and break down the primary structure of the food proteins. Preterm infants produce less gastric acid in the first week of life [4] and less gastric pepsin than term infants $[5,6]$, likely resulting in a lower capacity to digest milk proteins in the stomach. 
Recent research demonstrated that preterm infant gastric samples contain lower protease activity and less total proteolysis of milk proteins than term infant gastric samples [7].

Lower gastric protein digestion may limit the amount of amino acids available for absorption in the small intestine. Furthermore, altered protein digestion due to infant prematurity could lead to differential release of specific peptide fragments from mothers' milk proteins. Peptidomics is one technique commonly used to measure the digestion of milk proteins. Peptides released during in vitro digestions of bovine and human milk proteins have been analyzed several times [8,9], but in vitro digests often fail to adequately represent the immature infant GI system $[10,11]$. Piglet models have been used to measure formula digestion in the stomach, jejunum, and ileum [12], which is more representative of the infant GI system, but infant studies remain the gold standard. In preterm infants, it was shown that milk peptides increase in count and abundance from human milk to the infant stomach and increase in the stomach over time [13-15]. However, comparisons of preterm and term infants are sparse, even using in vitro and animal models. The only comparisons of total milk peptide release between preterm and term infants were performed on human milk and infant stool [16,17], and only milk immunoglobulin peptides have been compared in preterm and term gastric samples [18].

Differences in milk protein digestion are significant beyond the ability to release amino acids for absorption. Milk proteins contain an array of encrypted fragments that are released upon partial proteolysis; these fragments have an array of bioactive functions, including antimicrobial [19], immunomodulatory [20], antihypertensive [21], opioid [22], and intestinal wound healing [23,24]. Several of these peptides have been identified in human milk samples and infant digesta [13]. Lower release of these bioactive peptides in preterm compared with term infants could contribute to preterm infants' increased risk of negative health outcomes.

The purpose of this study was to compare the peptide profiles of the milks of preterm- and term-delivering mothers and the gastric samples of term and preterm infants. Although previous studies have identified that preterm infant stomachs may have reduced protein digestion capacity, the impact of this immaturity on the release of bioactive peptides from human milk remains unknown. The peptidomic comparisons in this study will lead to a deeper understanding of the specific limitations in the release of bioactive peptides from milk protein in the preterm infant stomach to enable future research examining the biological relevance of these differences to preterm infant health outcomes.

\section{Materials and Methods}

\subsection{Participants and Sample Collection}

This study was approved by the institutional review boards of the University of California, Davis (UC Davis) and Oregon State University, Corvallis, OR, USA. Human milk and infant gastric samples were collected from nine preterm-delivering mother-infant pairs ranging in GA at birth from 24 to 32 weeks and birth weight from $620-1610 \mathrm{~g}$ during 8-41 days of postnatal age at the UC Davis Children's Hospital Neonatal Intensive Care Unit in Sacramento, CA. Human milk and infant gastric samples were also collected from four term infants with a GA of 38-40 weeks and birth weight from 3360-3837 g during 14-42 days of postnatal age. Infants enrolled in this observational study each had health issues but no overt GI tract issues. The infants' conditions precluded normal breastfeeding; therefore, a nasogastric feeding tube was placed into each infant. Breast milk samples (unfortified) were collected by pumping on-site or at home with clean electric breast pumps into sterile plastic containers and stored immediately at $-20{ }^{\circ} \mathrm{C}$. The breast was cleaned with water on a washcloth (no soap or alcohol) before pumping. The human milk feedings (fortified with bovine-based human milk fortifier or high-calorie infant formula for preterm and term infants, respectively) were delivered via the nasogastric tubes over $30 \mathrm{~min}$. Two hours after the initiation of feeding, a fraction of each infant's gastric contents was collected in a $3 \mathrm{~mL}$ syringe back through the feeding tube via suction. Gastric samples were placed into sterile plastic vials and stored immediately at $-20^{\circ} \mathrm{C}$. Human milk and gastric samples were transported to Oregon State University on dry ice and stored at $-80^{\circ} \mathrm{C}$. 


\subsection{Sample Preparation}

Human milk and gastric samples were thawed at $4{ }^{\circ} \mathrm{C}$. Afterwards, samples were centrifuged at $4226 \times g$ for $10 \mathrm{~min}$ at $4{ }^{\circ} \mathrm{C}$, placed on ice, and the infranate was collected by pipette from below the upper fat layer. Milk proteins were then precipitated from the skimmed milk by addition of $400 \mu \mathrm{L}$ of $240 \mathrm{~g} / \mathrm{L}$ trichloroacetic acid. After mixing for $10 \mathrm{~s}$ with a vortex mixer, the samples were centrifuged at $4000 \times g$ for $10 \mathrm{~min}$ at $4{ }^{\circ} \mathrm{C}$ and $600 \mu \mathrm{L}$ of the supernatant containing the peptides was collected. Trichloroacetic acid, salts, oligosaccharides, and lactose were removed from the peptide solution and peptides were extracted using C18 reverse-phase preparative chromatography 96-well plates (Glygen, Columbia, MD, USA) as previously described [25]. The sample eluate was transferred to a new labeled tube after each centrifugation. The peptide solutions were frozen at $-80^{\circ} \mathrm{C}$ and lyophilized using a freeze-dry system (Labconco FreeZone 4.5 L, Kansas City, MO, USA). After drying, the samples were rehydrated in $0.1 \%$ formic acid in water to their initial amount.

\subsection{Liquid Chromatography (LC) Nano-Electrospray Ionization Mass Spectrometry}

The samples were loaded onto a $180 \mu \mathrm{m} \times 20 \mathrm{~mm}, 5 \mu \mathrm{m}$ bead $2 \mathrm{G}$ nanoAcquity UPLC trap column (reverse phase) for enrichment and online desalting, and then onto a $100 \mu \mathrm{m} \times 100 \mathrm{~mm}, 1.7 \mu \mathrm{m}$ bead Acquity UPLC Peptide BEH C18 column (Waters Corporation, Milford, MA, USA) for analytical separation on a nanoAcquity UPLC (Waters Corporation) directly connected with a nanospray source. The LC eluent was set up as previously described [25].

The mass spectrometry (MS) instrument used was a Thermo Scientific Orbitrap Fusion Lumos. Spectra were collected with positive-ionization mode with an electrospray voltage of $2400 \mathrm{~V}$. The MS scan range was $400-1500 \mathrm{~m} / \mathrm{z}$ at a resolution of $120 \mathrm{~K}$. The automatic gain control target was set to $4.0 \times 10^{5}$, with a maximum injection time of $50 \mathrm{~ms}$. The fragmentation mode was set to collision-induced dissociation, and the collision energy was 35\%. The MS cycle time was set to $3 \mathrm{~s}$, with data-dependent analysis and automated precursor peak selection. Precursors were excluded (within $10 \mathrm{ppm}$ mass error) after one fragmentation for $60 \mathrm{~s}$. Precursors were selected for fragmentation based on the following criteria: most intense peaks, ion-intensity threshold $5.0 \times 10^{3}$, and charge state $2-7$. Fragments were detected with the ion trap with an automatic scan range.

The collected spectra were analyzed by database searching in Thermo Proteome Discoverer (v2.1.0.81) using an in-house human milk protein sequence database. Potential modifications allowed included phosphorylation of serine and threonine and oxidation of methionine. Only peptides identified with high confidence were included $(p<0.01)$, and peptide sequences with multiple modifications were grouped into a single peptide for counts. Counts measured the number of unique peptide sequences identified in a sample. Abundance measured the area under the curve of the eluted peak (ion intensity).

\subsection{Protein Concentration}

The protein concentration in human milk and gastric samples prior to sample preparation were measured with the bicinchoninic acid protein assay.

\subsection{Bioactive Peptide Prediction}

Peptides identified in milk and gastric samples were examined for homology with literature-identified bioactive peptides using our Milk Bioactive Peptide Database (MBPDB, http://mbpdb.nws.oregonstate. edu/) [26]. The MBPDB is a comprehensive database covering all known milk bioactive peptides. The search was performed as a sequence search that searches for bioactive peptides matching the input peptide sequence. The "similarity threshold" was set to $80 \%$. In the result file, "Get extra output" was included to obtain the specific percentage similarity between the query sequence and the database sequence. 


\subsection{Statistics}

Differences in preterm and term overall peptide intensity and count as well as peptide count per protein were determined using an analysis of variance with Tukey's HSD post hoc test in the statistical program RStudio.

For protein differences, data were analyzed with Perseus v.1.6.1.1 (Planegg, Germany). Once data were loaded into the software, they were log2-transformed and grouped into preterm milk, term milk, preterm gastric, and term gastric. Data were filtered by rows based on valid values for occurrence in $\geq 75 \%$ of samples in at least one group. A volcano plot was constructed using the volcano plot function in Perseus based on $\log 2$ fold change on the $\mathrm{x}$-axis and $-\log (p$-value) on the y-axis. An ANOVA test was performed in Perseus to determine whether there were significant differences between the abundance of amino acids positioned at the $\mathrm{P} 1$ or $\mathrm{P} 1^{\prime}$ position of the enzymatic cleavage sites and between the abundance of bioactive peptides in preterm and term mother's milk and the infant gastric samples. Two sample $t$-tests were used to compare each amino acid in the heat map. Throughout the paper, significance was defined as $p<0.05$.

\section{Results}

\subsection{Demographic Information}

Demographic details for the preterm and term mother-infant pairs are presented in Table 1. Human milk peptidomic analysis was performed on unfortified milk samples. The gastric aspirates from the preterm infants were obtained following feeding of human milk that was fortified with bovine-based human milk fortifier. The gastric aspirates from the term infants were obtained following fortification of human milk with high-calorie infant formula.

Table 1. Demographic information for the mother-infant pairs sampled for milk and gastric contents. Data are presented as mean \pm standard error (range).

\begin{tabular}{ccc}
\hline Age/Weight & Preterm $(\boldsymbol{n = 9 )}$ & Term $(\boldsymbol{n}=\mathbf{4})$ \\
\hline Gestational age at birth, weeks & $26.8 \pm 1.0(24-32)$ & $39.0 \pm 0.5(38-40)$ \\
Postnatal age at collection, day & $24.6 \pm 3.8(8-41)$ & $25.0 \pm 6.5(14-42)$ \\
Birth weight, $g$ & $930.6 \pm 106.5(620-1610)$ & $3717.8 \pm 119.3(3360-3837)$ \\
Mother's age, year & $31.6 \pm 1.9(18-40)$ & $20.8 \pm 2.8(18-29)$ \\
\hline
\end{tabular}

\subsection{Protein Concentration and $p H$}

The protein concentration of the unfortified preterm human milk was $16.1 \pm 0.5 \mathrm{mg} / \mathrm{mL}$ and that of term human milk was $14.6 \pm 1.9 \mathrm{mg} / \mathrm{mL}$. The gastric aspirates collected two hours after feeding contained $17.07 \pm 1.5 \mathrm{mg} / \mathrm{mL}$ and $17.9 \pm 4.5 \mathrm{mg} / \mathrm{mL}$ for preterm and term infants, respectively. The $\mathrm{pH}$ of the preterm human milk was $6.29 \pm 0.1$, and the $\mathrm{pH}$ of the term human milk was $6.52 \pm 0.11$. The $\mathrm{pH}$ of the gastric aspirates was $4.41 \pm 0.37$ in preterm infants and $4.51 \pm 0.24$ in term infants.

\subsection{Total Peptide Identification}

This study compared the number of peptides released from the proteins present in term and preterm mothers' milk and those released in the preterm and term infant stomachs. A total of 2240 unique peptides were identified in the 13 human milk samples from 79 milk proteins. Of these, 834 were found in preterm milk and not term milk, while 384 were found in term mothers' milk and not preterm mothers' milk (Figure 1). The remaining 1022 were identified in both term and preterm mothers' milks (Figure 1). Of the milk peptides, 85 were found in all mothers' milk samples, and accounted for $70.9 \pm 4.4 \%$ of the total milk peptide abundance. 


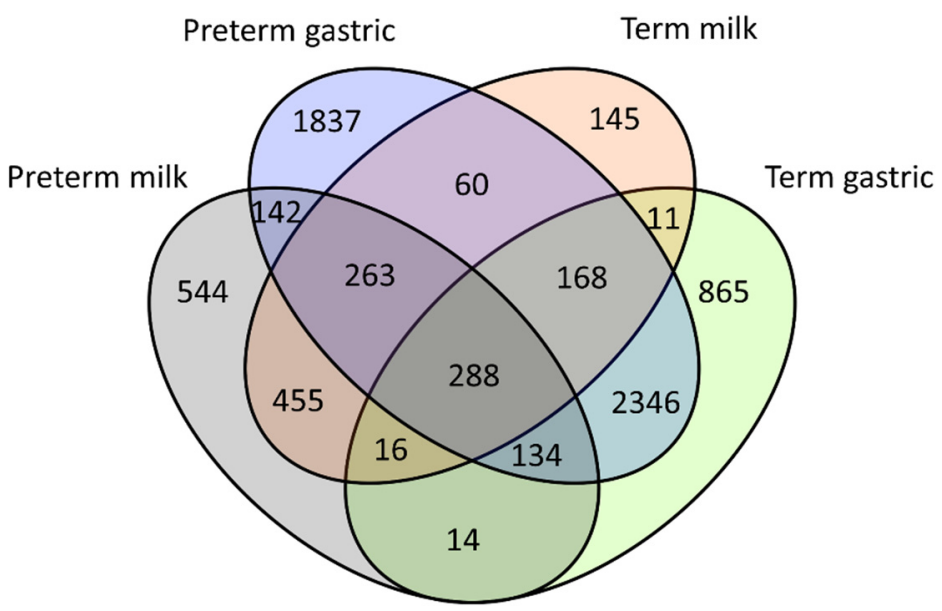

Figure 1. Venn diagram showing number of peptides identified in each sample group and their overlaps with other samples groups.

A total of 6144 unique peptides were identified in the 13 infant gastric samples deriving from 127 different human milk proteins and 89 different bovine milk proteins. Of these, 2302 were identified in preterm gastric and not term gastric, whereas 906 were identified in term gastric and not preterm gastric (Figure 1). One hundred and twelve peptides were present in all the gastric samples, accounting for $34.3 \pm 5.3 \%$ of the total gastric peptide abundance. Seven peptides were identified in all milk and gastric samples (human $\alpha_{\mathrm{s} 1}$-casein $\mathrm{R}^{1}-\mathrm{N}^{35}$ and $\mathrm{R}^{10}-\mathrm{N}^{35}$, human $\beta$-casein $\mathrm{E}^{2}-\mathrm{K}^{18}, \mathrm{~L}^{130}-\mathrm{T}^{145}, \mathrm{~L}^{188}-\mathrm{V}^{211}$, $\left.\mathrm{L}^{189}-\mathrm{V}^{211}, \mathrm{P}^{201}-\mathrm{V}^{211}\right)$.

The amino acid length of the identified peptides was investigated in milk and gastric samples. The combined data for preterm and term infants showed an increased number of short peptides in the gastric compared with the milk samples (Figure 2).

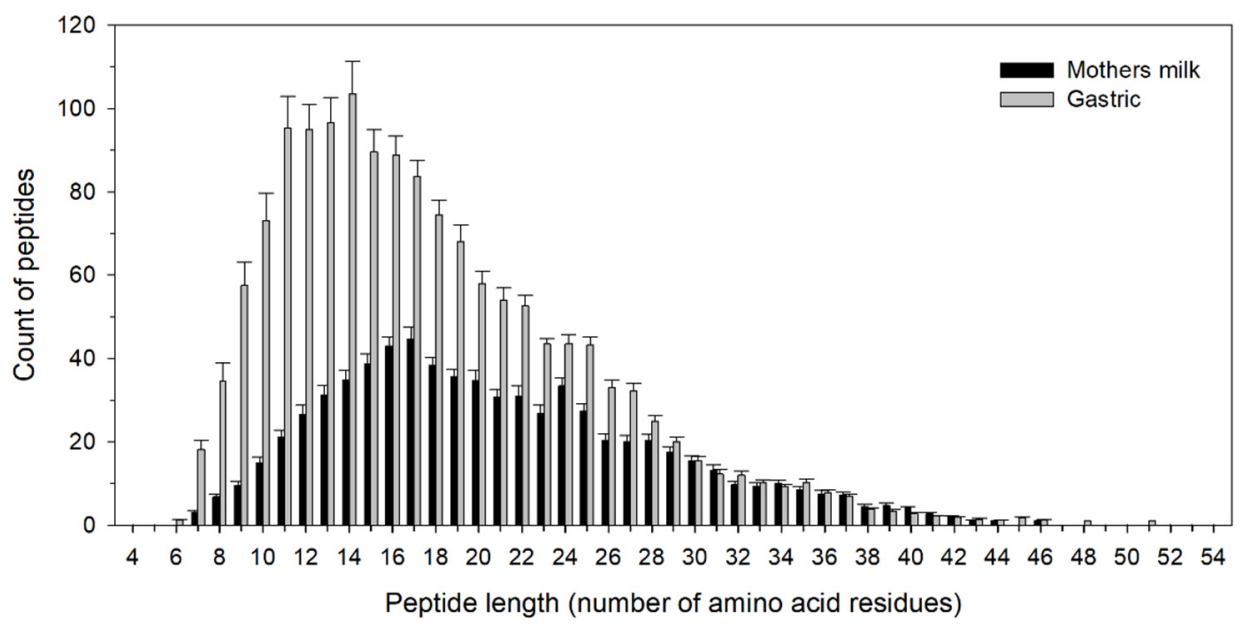

Figure 2. Distribution of peptide length in milk and gastric samples. Data are presented as mean \pm standard error, $n=13$.

\subsection{Comparison of Peptide Profile between Preterm and Term Mothers' Milk and Infant Gastric Contents}

On average, $725.0 \pm 54.3$ and $595.0 \pm 81.5$ peptides were identified in the preterm and term mothers' milk samples $(p=0.23)$, respectively (Figure 3A). The average total peptide abundance tended to be higher in preterm mothers' milk than in term mothers' milk $(p=0.09)$. The majority of peptides in mother's milk derived from, in order of peptide count pooled across term and preterm, human $\beta$-casein, human osteopontin, human polymeric immunoglobulin receptor, human $\alpha_{\mathrm{s} 1}$-casein, human butyrophilin subfamily 1 member A1, human bile salt-activated lipase, human $\mathrm{k}$-casein, 
and human mucin-1. The count of peptides derived from $\alpha_{\mathrm{s} 1}$-casein and polymeric immunoglobulin receptor was higher in the preterm mothers' milk than in term mothers' milk (Table 2).
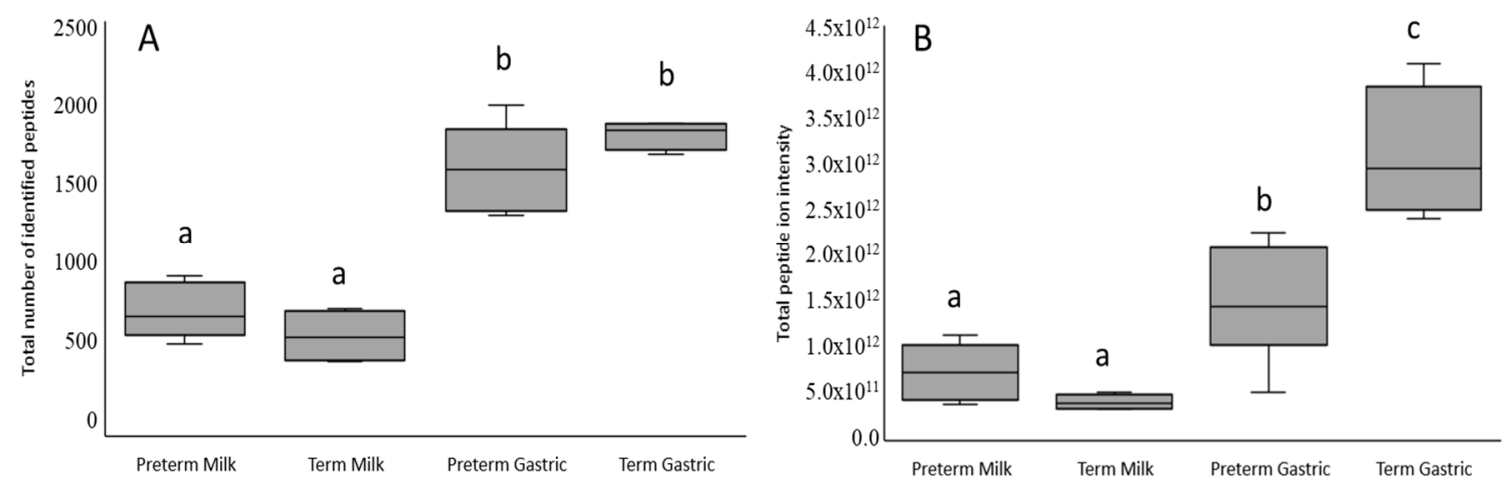

Figure 3. Differences in total number of peptides identified in mothers' milk and infant gastric. Total count (A) and abundance (B) of peptides identified in preterm and term infant gastric samples (human milk fortified with bovine-based human milk fortifier or high-calorie infant formula, respectively) and their mothers' milk (unfortified). Different letters indicate significantly different values $(p<0.05)$.

Table 2. Proteins with the highest number of identified peptides ${ }^{1}$.

\begin{tabular}{ccccc}
\hline \multirow{2}{*}{ Protein } & \multicolumn{2}{c}{ Count in Milk $^{2}$} & \multicolumn{2}{c}{ Count in Gastric Contents $^{3}$} \\
\cline { 2 - 5 } & Preterm & Term & Preterm & Term \\
\hline Bovine $\beta$-casein & & & $197 \pm 9$ & $249 \pm 18$ \\
Human $\beta$-casein & $286 \pm 27$ & $228 \pm 34$ & $348 \pm 28$ & $308 \pm 6$ \\
Human osteopontin & $127 \pm 22$ & $130 \pm 16$ & $66 \pm 9$ & $58 \pm 9$ \\
Bovine $\alpha_{\text {s1-casein }}$ & & & $132 \pm 8$ & $136 \pm 14$ \\
Bovine -casein & & & $109 \pm 5$ & $120 \pm 18$ \\
Human $\alpha_{\text {s1-casein }}^{*}$ & $77 \pm 8^{*}$ & $49 \pm 8$ & $106 \pm 11$ & $75 \pm 8$ \\
Human polymeric & $84 \pm 5^{*}$ & $64 \pm 6$ & $67 \pm 3$ & $58 \pm 6$ \\
immunoglobulin receptor & $0 \pm 0$ & $1 \pm 1$ & $80 \pm 10 *$ & $41 \pm 5$ \\
Human lactoferrin & & & $45 \pm 4$ & $50 \pm 4$ \\
Bovine $\alpha_{\text {s2-casein }}$ & & & $63 \pm 8$ & $82 \pm 9$ \\
Bovine $\beta$-lactoglobulin & & &
\end{tabular}

${ }^{1}$ Results are shown as mean \pm standard error. Asterisks $\left(^{*}\right)$ indicate significant differences between preterm and term infants $(p<0.05) ;{ }^{2}$ Unfortified human milk; ${ }^{3}$ Preterm infants were fed human milk fortified with bovine-based human milk fortifier and term infants were fed human milk fortified with high-calorie infant formula.

On average, $1698.7 \pm 113.4$ and $1816.3 \pm 43.5$ peptides were identified in preterm and term infant gastric samples (Figure 3B) $(p=0.35)$, which was for both preterm and term infants significantly higher than in the milk samples $(p<0.001)$. The finding that the number of peptides present in the stomach was higher than in milk conforms with a previous study [15]. The average total peptide abundance was significantly higher in term infant gastric contents compared with preterm infant gastric contents $(p<0.001)$. The total abundance of peptides increased significantly from mothers' milk to infant gastric contents, in both preterm and term infants.

The majority of peptides derived from - in order of peptide count pooled across term and preterm gastric samples-human $\beta$-casein, bovine $\beta$-casein, bovine $\alpha_{\mathrm{s} 1}$-casein, bovine $\mathrm{k}$-casein, human $\alpha_{\mathrm{s} 1}$-casein, bovine $\beta$-lactoglobulin, human osteopontin, human polymeric immunoglobulin receptor, human lactoferrin, bovine $\alpha_{\mathrm{s} 2}$-casein (Table 2). The count of peptides identified from lactoferrin was significantly higher in the preterm infant stomach compared with the term infant stomach.

\subsection{Individual Protein Digestion}

To investigate from which specific proteins the release of peptides was significantly different between preterm and term infant samples, we constructed a volcano plot showing the total abundance 
of peptides from each protein in either preterm or term milk or gastric samples (Figure 4). We included only proteins that were identified in at least $75 \%$ of samples in either preterm or term milk or gastric samples. Twenty-five proteins in milk samples and 106 proteins in the gastric samples met these criteria. In milk, peptides from 17 proteins (68\% of the proteins meeting the criteria) were more abundant in preterm mothers' milk than in term mothers' milk, but only peptides from $\alpha_{\mathrm{s} 1}$-casein were significantly more abundant in preterm mothers' milk compared with term mothers' milk. In gastric samples, peptides from $97(92 \%)$ proteins trended towards greater abundance in term infants than in preterm infants. The peptide abundances of eleven of these proteins were significantly higher in term infant gastric samples than in preterm infant gastric samples. The eleven significantly different proteins were human Ig gamma-1, human gelsolin, human apolipoprotein A-I 1, human $\alpha$-2-HS-glycoprotein, human $\alpha$-enolase, human fibrinogen, bovine osteopontin, bovine heat shock 70kDa protein $1 \mathrm{~A}$, human serum albumin, human peptidyl-prolyl cis-trans isomerase A, and human apolipoprotein A-II.
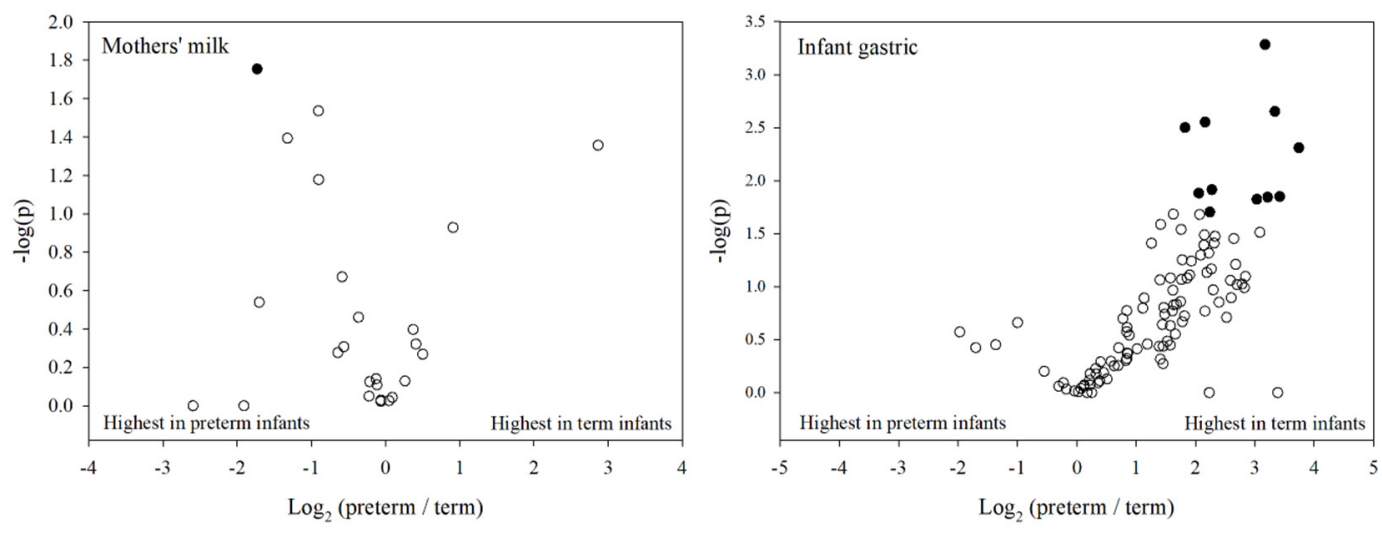

Figure 4. Volcano plots depicting fold change in total peptide intensity from individual proteins ( $x$-axis, logarithmic) and $p$-value (y-axis, logarithmic) between term and preterm infant milk and gastric samples. Filled circles indicate the protein was significantly different between preterm and term infants $(p<0.05)$, whereas the hollow circles are non-significant.

For comparison between preterm and term infants at a peptide level, we excluded all peptides that were present in less than $75 \%$ of samples in either preterm or term milk or gastric samples. After this filtering, 1408 peptides remained, of which 439 peptides were in the human milk samples and 1049 were in the infant gastric samples. Although this filtering step largely reduced the number of peptides, the remaining peptides accounted for an average of $88 \%$ of the total ion intensity identified before filtering. The difference and fold change between preterm and term infants of these peptides are shown in Figure 5. The majority of peptides (279 out of 439) showed a trend towards higher abundance in preterm mothers' milk compared with term mothers' milk, of these 19 were significantly more abundant. In the infant gastric contents, the majority of peptides (770 out of 1049) trended towards greater abundance in term infants compared with preterm infants, of which 80 were significantly higher.

Heatmap analysis of peptide release across their parent protein sequences demonstrates that peptides were released at similar regions across $\alpha_{s 1}$-casein, $\beta$-casein, and osteopontin sequences between preterm and term infants in both milk samples and gastric samples (Figure 6). Based on ion intensity, the quantity of peptides from the N-terminal of human $\beta-C N$ was significantly higher in term milk compared with preterm milk. The ion intensity of peptides from the C-terminal of human $\alpha_{\mathrm{s} 1}$-casein was significantly higher in preterm milk than in term milk. Amino acid residues 231-250 of human osteopontin were significantly higher in term milk compared with preterm milk. 

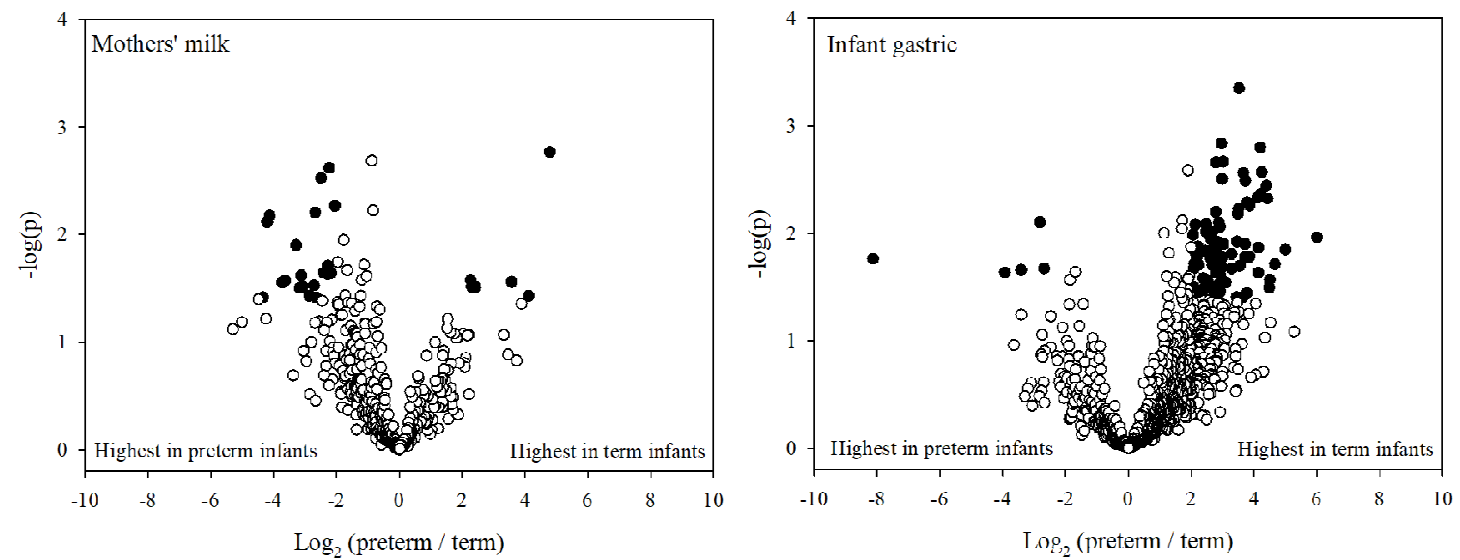

Figure 5. Volcano plots depicting fold change in individual peptide intensity ( $x$-axis, logarithmic) and $p$-value ( $y$-axis, logarithmic) between term and preterm infant milk and gastric samples. Filled circles indicate the peptide was significantly different between preterm and term infants $(p<0.05)$, whereas the hollow circles are non-significant.

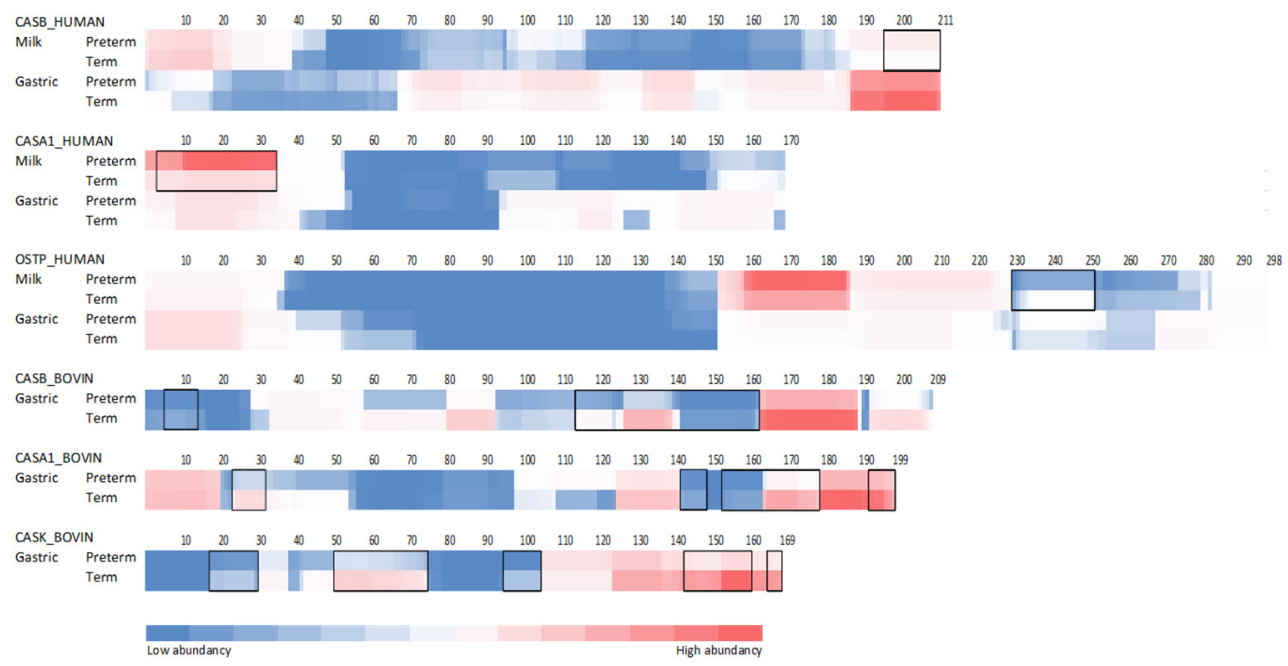

Figure 6. Abundance of peptides identified in mother's milk and gastric samples from term and preterm infants mapped to the sequence of human and bovine $\beta$-casein (CASB), osteopontin (OSTP), $\alpha_{\mathrm{s} 1}$-casein (CASA1), and $k$-casein (CASK). Areas with black borders mark significant difference $(p<0.05)$ between ion intensity of peptides at each amino acid site.

In gastric samples, there was a significantly higher ion intensity of peptides from human osteopontin at amino acid residues position 215-252. Neither human $\beta$-casein nor human $\alpha_{\mathrm{s} 1}$-casein gastric peptide intensities differed between preterm and term infants. For bovine $\beta$-casein and bovine $\alpha_{\mathrm{s} 1}$-casein, the ion intensity of peptides deriving from their C-termini were significantly higher in the gastric contents of term infants compared with preterm infants. The ion intensity of peptides deriving from several areas of the bovine $\mathrm{k}-\mathrm{CN}$ were higher in the gastric contents of term infants compared with that of preterm infants (Figure 6).

\subsection{Analysis of Proteolytic Cleavage Sites}

We examined the amino acids located at P1 and P1' of the C- and N-termini of the identified peptides to link cleavage patterns with known proteases. P1 is the amino acid positioned just prior to the enzymatic cleavage site and $\mathrm{P} 1^{\prime}$ is the amino acid positioned just after the enzymatic cleavage site in the protein sequence. As some of the enzymes present and active in milk and infant gastric contents 
have high specificity for certain amino acids at either the $\mathrm{P} 1$ or $\mathrm{P}^{\prime}$ position, we used the cleavage sites to identify which specific enzymatic activity caused the release of identified peptides.

In human milk, most of the cleavages in milk proteins were after an arginine or a lysine, which matches the cleavage specificity of plasmin, kallikrein 6 and 11, and thrombin present in human milk [27].

In the gastric samples of preterm and term infants, most cleavages occurred after a leucine, which matches the cleavage specificity of pepsin and cathepsin D (Figure 7). Peptides resulting from cleavage after a leucine were significantly higher in term infants compared with preterm infants, indicating higher activity of pepsin and cathepsin $\mathrm{D}$ in term infants. In gastric samples, peptides with a proline or valine at the $\mathrm{P}^{\prime}$ position were also significantly higher in term infants than in preterm infants. No gastric or milk enzyme with specificity for proline or valine at $\mathrm{P} 1^{\prime}$ position is known.

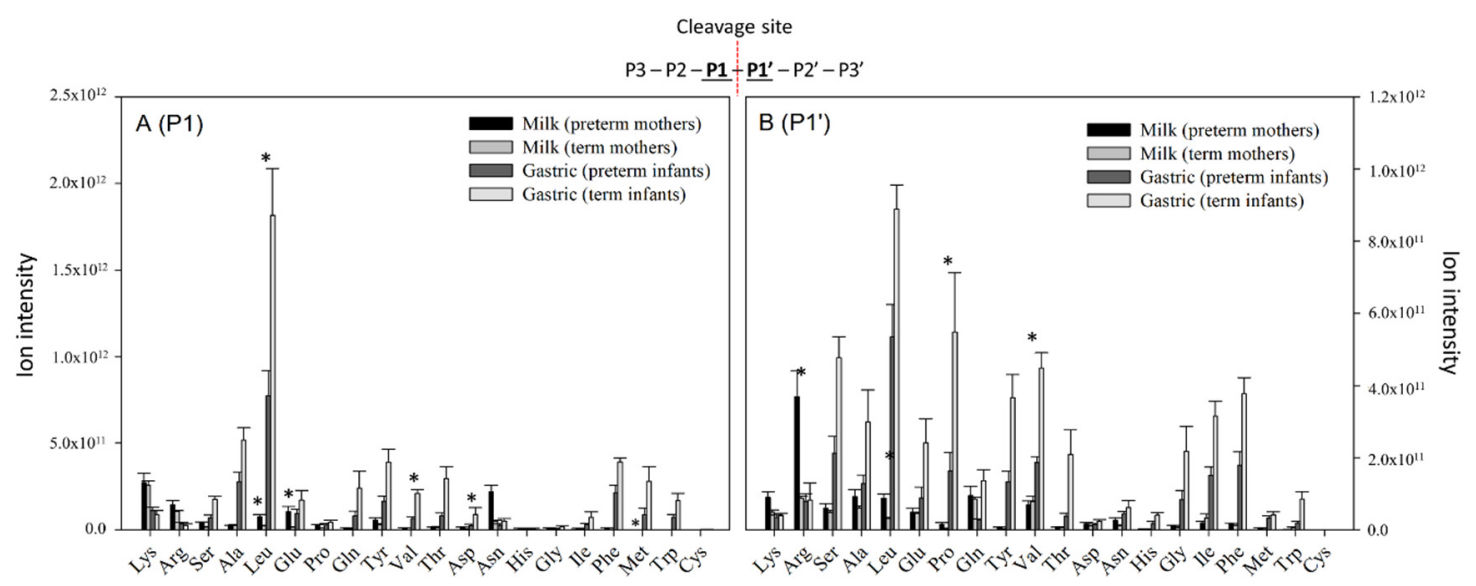

Figure 7. Total ion intensity of peptides distributed according to their P1 (A) and P1' (B) cleavage site amino acid in term and preterm infants' mothers' milk and their gastric samples. Asterisk marks significant difference between preterm and term infants. $\mathrm{P} 3-\mathrm{P} 3^{\prime}$ are the amino acids positioned around the cleavage site.

\subsection{Bioactive Peptide Comparison between Preterm and Term Infants}

From the total number of identified peptides in milk and gastric samples, we identified 436 peptides with high similarity to a known bioactive peptide ( $>80 \%$ sequence homology) deriving from bovine milk proteins (207 with angiotensin-converting enzyme (ACE)-inhibitory activity, 135 with antimicrobial activity, 22 with dipeptidyl peptidase IV inhibitory activity, 7 with antioxidant activity, and 65 with other biological functions) and 145 peptides deriving from human milk proteins (54 with ACE-inhibitory activity, 48 with antimicrobial activity, 40 with cell proliferation-stimulatory activity, and 3 with other biological functions). Five peptides found in the milk and 35 peptides found in gastric samples were identical to a known bioactive peptide.

Forty and 180 of these bioactive peptides were present in at least $75 \%$ of the milk or gastric samples, respectively, and were compared between preterm and term infants (Figure 8). Of the 40 peptides identified in at least $75 \%$ of milk samples, 4 were significantly higher in preterm mother's milk compared with term mothers' milk (three were antimicrobial and one stimulated cell proliferation). One additional peptide with antimicrobial activity was only identified in preterm mothers' milk. Of the 180 potentially bioactive peptides identified in more than 75\% of infant gastric samples, 145 trended towards greater abundance in term infants than in preterm infants. One peptide with potential antimicrobial activity was significantly higher in preterm gastric contents, whereas 21 peptides were significantly higher in the gastric contents of term infants. Of these 21 peptides significantly higher in term gastric samples, 12 had antimicrobial activity, four stimulated cell proliferation, and four had ACE-inhibitory activity. Additionally, one peptide with antimicrobial activity was found only in preterm infants, whereas six peptides with ACE-inhibitory and four peptides with antimicrobial activity were only found in term infants. 

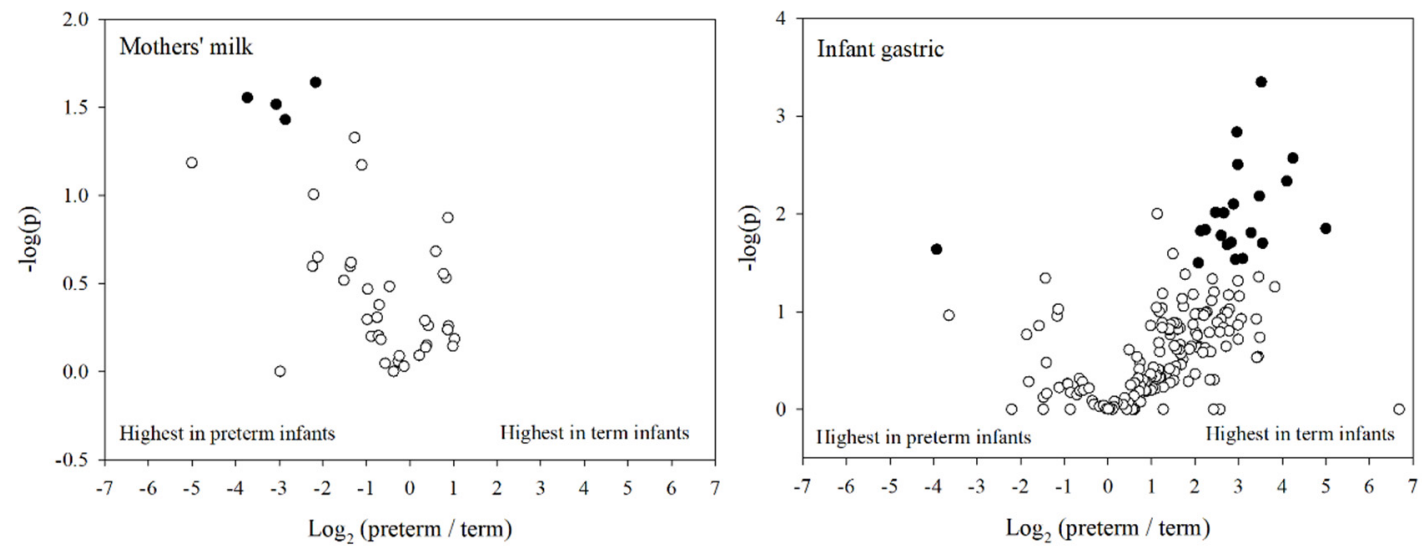

Figure 8. Volcano plots depicting fold change in bioactive peptide intensity ( $x$-axis, logarithmic) and $p$-value ( $y$-axis, logarithmic) between term and preterm infant milk and gastric samples. Filled circles indicate the peptide was significantly different between preterm and term infants $(p<0.05)$, whereas the hollow circles are non-significant.

Of the eight peptides that were identified in all milk and gastric samples, human $\beta$-casein $E^{2}-K^{18}$ is $94 \%$ homologous with a known cell-proliferation-activating peptide [28] and human $\beta$-casein $\mathrm{L}^{188}-\mathrm{V}^{211}$ and $\mathrm{L}^{189}-\mathrm{V}^{211}$ have $89 \%$ and $85 \%$ homology, respectively, with a known antimicrobial peptide [29]. Human $\beta$-casein $\mathrm{L}^{188-} \mathrm{V}^{211}$ was significantly higher in abundance in preterm milk compared with term milk, whereas in the gastric contents it was significantly higher in term infants compared with preterm infants.

\section{Discussion}

In this work, we examined the peptide profile of human milk and infant gastric samples collected from preterm-delivering and term-delivering mother-infant pairs. Peptidomics enables determination of specifically how proteins are digested within in vivo samples. Peptidomics has previously been applied to identify milk peptides in human milk [16,30,31], infant formula [32], preterm infant gastric samples [13-15], and infant stool samples [17]. However, to date, no peptidomics studies have been performed to compare milk protein digestion and the release of bioactive peptides within the stomachs of term and preterm infants.

The initial protein concentration in the human milk before fortification was not different between preterm and term infant mothers' milk. The gastric protein concentrations were lower than what the summed protein concentration of the human milk and added fortification would be, which was likely due to digestion and dilution with gastric fluids in the stomach. These results align with a previous study [33]. The $\mathrm{pH}$ values of the gastric contents aligned with our previous study [7]. Although other previous studies have reported lower gastric $\mathrm{pH}$ values for infants of these age ranges and differences in $\mathrm{pH}$ between infants of different gestational age [4,34], these studies did not take gastric $\mathrm{pH}$ measurements after enteral milk feedings. The buffering capacity of milk proteins and salts present in the aspirates could explain the increased and consistent $\mathrm{pH}$ ranges for these infants.

The Orbitrap Fusion Lumos mass spectrometer used in this study allowed identification of a large number of peptides in each sample. The peptide profiles were more comprehensive than in a previous study of infant gastric digestion [14], which provides more complete data as basis for conclusion delivered by this study. The abundance of peptides identified in preterm-delivering mothers' milk tended to be higher than that in term-delivering mothers' milk, and, on an individual protein level, we observed a higher count and abundance of $\alpha_{\mathrm{s} 1}$-casein peptides in preterm mothers' milk compared with term milk. In the first few weeks of life, the milk of preterm-delivering mothers is more nutrient-rich than that of term-delivering mothers [35]. The increased abundance of peptides could be related to the increased protein content in preterm milk. 
The total count and abundance of peptides increased significantly and the average amino acid length of peptides decreased from mothers' milk to infant gastric contents in both preterm and term infants. Peptide abundance was significantly higher in term infant gastric samples than in those of preterm infants. This finding indicates a higher break-down of protein in the term infant's stomach compared with preterm infants and conforms with our previous data showing that preterm infants have lower protease activity in the stomach compared with term infants [7]. However, it should be noted that peptides were only identified in gastric samples collected $2 \mathrm{~h}$ after the initiation of feeding. In preterm infants, peptides continue to be released in the stomach up to $3 \mathrm{~h}$ after feeding [15]. There may be differences in the rate of gastric digestion and gastric emptying between preterm and term infants such that results may be different in gastric samples collected at a shorter or longer time after feeding.

Interestingly, we did not detect significant amounts of peptides from bovine proteins in the milk samples, however a large number of peptides from bovine $\beta$-lactoglobulin were present in the stomach, likely from the fortification of the milk prior to feeding. The large amount of bovine $\beta$-lactoglobulin peptides is counter-intuitive as previous in vitro studies have demonstrated that bovine $\beta$-lactoglobulin is partly resistant to digestion by gastric pepsin [36,37]. This peptidomics approach, however, does not allow determination of the remaining concentration of intact $\beta$-lactoglobulin.

The amino acid cleavage site-based enzyme analysis showed that the major cleavage site was after leucine in the gastric samples. These findings are logical as pepsin is the main gastric protease. Cathepsin D is present but inactive in milk and could be activated by the low $\mathrm{pH}$ of the stomach. The abundance of peptides resulting from cleavage after a leucine was significantly higher in the gastric samples of term infants than in preterm infants. This finding provides supporting evidence for the hypothesis that pepsin activity is higher in the stomachs of term infants compared with preterm infants, which was previously indicated by enzyme activity assays of gastric aspirates of preterm and term infants [7]. The proposed increased enzyme activity of pepsin in the term infant stomach compared with the preterm infant stomach supports the increased abundance of peptides identified in the term infant gastric samples compared with preterm infants' gastric samples. This study is one of few studies comparing preterm and term digestion. The result reveals that preterm infants have lower digestive capacity than term infants, and therefore may have a limited ability to break-down milk proteins for nutrient absorption.

The differences in the peptide profiles of milk and gastric samples from either preterm or term infants could indicate a corresponding difference in the release of bioactive peptides. Therefore, we compared the identified peptides with the comprehensive database of known bioactive peptides derived from milk proteins (Milk Bioactive Peptide Database, MBPDB). Twenty-one biologically active peptides were significantly higher in term infants' gastric samples, compared with only one peptide that was significantly higher in the preterm infant gastric samples. Though by far the most common functional attribution of milk peptides is ACE-inhibitory [26], the dominant bioactivity of peptides that were significantly higher in term infant gastric contents compared with preterm was antimicrobial activity. Thus, despite receiving a higher initial abundance of peptides in their milk, preterm infants have reduced total and antimicrobial peptide release in the stomach. The lower gastric peptide release seen in this study could be partially responsible for preterm infants' slower growth and increased risk of infection. An initial decrease of peptides in the stomach could put the infants at a disadvantage by the time the feed reaches the intestine, where amino acids are absorbed and antimicrobial peptides are able to have effect [38]. The inclusion of proteases or supplemental bioactive milk peptides to the feed could compensate for the reduced digestion capacity of the preterm infant and should be studied further. Our study did not include identification of short peptides ( $2-5$ amino acids long). As a high number of the known bioactive peptides are within this amino acid length range [39], potentially more bioactive peptides are present in mothers' milk and infant gastric samples than are reported herein. 
A limitation of this study is that term infant samples were collected from infants whose health circumstances required nasogastric tubes. Though these conditions are not known to affect digestion, whether the results from term infants are generalizable to the healthy term infant population is unknown.

\section{Conclusions}

This research contributes to a better understanding of gastric digestion of human and bovine milk proteins in preterm and term infants, an essential step in understanding overall protein digestion in these infants. We found an increase in peptide count and abundance and a decrease in amino acid length of peptides from mother's milk to infant gastric contents. The overall higher abundance of peptides in term infant gastric contents compared with preterm infant gastric contents indicates a higher digestive capacity in term infants compared with preterm infants. Most individual proteins showed higher digestion in term gastric contents compared with preterm, and eleven of these proteins were significantly more digested, including human Ig gamma and bovine osteopontin. The lower level of pepsin/cathepsin D cleavage sites in the peptidomics data indicates that the apparent lower degree of protein digestion in preterm infants could be due to a lower gastric pepsin or cathepsin D activity compared with term infants. The apparent lower proteolytic activity in the preterm infant stomach resulted in a lower number of bioactive peptides, and particularly antimicrobial peptides, in their gastric samples compared with term infants. The lower level of antimicrobial peptides in the preterm infant stomach could represent lesser protection against pathogenic microbes than in term infants.

Author Contributions: Conceptualization, M.A.U., S.D.N. and D.C.D.; methodology, S.D.N., M.A.U. and D.C.D.; formal analysis, S.D.N. and R.L.B.; investigation, S.D.N.; data curation, S.D.N.; writing-original draft preparation, S.D.N., R.L.B. and D.C.D.; writing—review and editing, S.D.N., R.L.B., M.A.U. and D.C.D.; visualization, S.D.N.; supervision, D.C.D.; project administration, D.C.D.; funding acquisition, D.C.D. All authors have read and agreed to the published version of the manuscript.

Funding: This research was funded by the K99/R00 Pathway to Independence Career Award, Eunice Kennedy Shriver Institute of Child Health \& Development of the National Institutes of Health (R00HD079561) (DC Dallas), the United States Department of Agriculture (2018-67017-27521) and the Gerber Foundation (2017-1586).

Acknowledgments: The authors acknowledge the Mass Spectrometry Center at Oregon State University, which is supported in part by the National Institute of Health grant S10OD020111.

Conflicts of Interest: The authors declare no conflict of interest.

\section{References}

1. Martin, J.A.; Hamilton, B.E.; Osterman, M.J.; Driscoll, A.K.; Mathews, T.J. Births: Final data for 2015. In National Vital Statistics Reports: From the Centers for Disease Control and Prevention, National Center for Health Statistics, National Vital Statistics System; CDC: Atlanta, GA, USA, 2017; Volume 66, p. 1.

2. Richards, M.; Hardy, R.; Kuh, D.; Wadsworth, M.E. Birthweight, postnatal growth and cognitive function in a national uk birth cohort. Int. J. Epidemiol. 2002, 31, 342-348. [CrossRef] [PubMed]

3. Ehrenkranz, R.A.; Dusick, A.M.; Vohr, B.R.; Wright, L.L.; Wrage, L.A.; Poole, W.K. Growth in the neonatal intensive care unit influences neurodevelopmental and growth outcomes of extremely low birth weight infants. Pediatrics 2006, 117, 1253-1261. [CrossRef] [PubMed]

4. Kelly, E.J.; Newell, S.J.; Brownlee, K.G.; Primrose, J.N.; Dear, P.R. Gastric acid secretion in preterm infants. Early. Hum. Dev. 1993, 35, 215-220. [CrossRef]

5. Armand, M.; Hamosh, M.; Mehta, N.R.; Angelus, P.A.; Philpott, J.R.; Henderson, T.R.; Dwyer, N.K.; Lairon, D.; Hamosh, P. Effect of human milk or formula on gastric function and fat digestion in the premature infant. Pediatr. Res. 1996, 40, 429-437. [CrossRef]

6. Henderson, T.R.; Hamosh, M.; Armand, M.; Mehta, N.R.; Hamosh, P. Gastric proteolysis in preterm infants fed mother's milk or formula. Adv. Exp. Med. Biol. 2001, 501, 403-408. [PubMed]

7. Demers-Mathieu, V.; Qu, Y.; Underwood, M.A.; Borghese, R.; Dallas, D.C. Premature infants have lower gastric digestion capacity for human milk proteins than term infants. J. Pediatr. Gastroenterol. Nutr. 2018, 66, 816-821. [CrossRef] 
8. Wada, Y.; Lonnerdal, B. Bioactive peptides released from in vitro digestion of human milk with or without pasteurization. Pediatr. Res. 2015, 77, 546-553. [CrossRef]

9. Hodgkinson, A.J.; Wallace, O.A.M.; Smolenski, G.; Prosser, C.G. Gastric digestion of cow and goat milk: Peptides derived from simulated conditions of infant digestion. Food Chem. 2019, 276, 619-625. [CrossRef]

10. Torcello-Gómez, A.; Dupont, D.; Jardin, J.; Briard-Bion, V.; Deglaire, A.; Risse, K.; Mechoulan, E.; Mackie, A. The pattern of peptides released from dairy and egg proteins is highly dependent on the simulated digestion scenario. Food Funct. 2020, 11, 5240-5256. [CrossRef]

11. Ménard, O.; Bourlieu, C.; De Oliveira, S.C.; Dellarosa, N.; Laghi, L.; Carrière, F.; Capozzi, F.; Dupont, D.; Deglaire, A. A first step towards a consensus static in vitro model for simulating full-term infant digestion. Food Chem. 2018, 240, 338-345. [CrossRef]

12. Bouzerzour, K.; Morgan, F.; Cuinet, I.; Bonhomme, C.; Jardin, J.; Le Huërou-Luron, I.; Dupont, D. In vivo digestion of infant formula in piglets: Protein digestion kinetics and release of bioactive peptides. Br. J. Nutr. 2012, 108, 2105-2114. [CrossRef] [PubMed]

13. Nielsen, S.D.; Beverly, R.L.; Underwood, M.A.; Dallas, D.C. Release of functional peptides from mother's milk and fortifier proteins in the premature infant stomach. PLOS ONE 2018, 13, e0208204. [CrossRef] [PubMed]

14. Dallas, D.C.; Guerrero, A.; Khaldi, N.; Borghese, R.; Bhandari, A.; Underwood, M.A.; Lebrilla, C.B.; German, J.B.; Barile, D. A peptidomic analysis of human milk digestion in the infant stomach reveals protein-specific degradation patterns. J. Nutr. 2014, 144, 815-820. [CrossRef] [PubMed]

15. Beverly, R.L.; Underwood, M.A.; Dallas, D.C. Peptidomics analysis of milk protein-derived peptides released over time in the preterm infant stomach. J. Proteome. Res. 2019, 18, 912-922. [CrossRef] [PubMed]

16. Dallas, D.C.; Smink, C.J.; Robinson, R.C.; Tian, T.; Guerrero, A.; Parker, E.A.; Smilowitz, J.T.; Hettinga, K.A.; Underwood, M.A.; Lebrilla, C.B.; et al. Endogenous human milk peptide release is greater after preterm birth than term birth. J. Nutr. 2015, 145, 425-433. [CrossRef]

17. Beverly, R.L.; Huston, R.K.; Markell, A.M.; McCulley, E.A.; Martin, R.L.; Dallas, D.C. Milk peptides survive in vivo gastrointestinal digestion and are excreted in the stool of infants. Nutr. J. 2019, 150, 712-721. [CrossRef]

18. Demers-Mathieu, V.; Underwood, M.A.; Beverly, R.L.; Nielsen, S.D.; Dallas, D.C. Comparison of human milk immunoglobulin survival during gastric digestion between preterm and term infants. Nutrients 2018, $10,631$. [CrossRef]

19. Ali, E.; Nielsen, S.D.; Abd-El Aal, S.; El-Leboudy, A.; Saleh, E.; LaPointe, G. Use of mass spectrometry to profile peptides in whey protein isolate medium fermented by lactobacillus helveticus $\mathrm{lh}-2$ and lactobacillus acidophilus la-5. Front. Nutr. 2019, 6, 152. [CrossRef]

20. Reyes-Diaz, A.; Gonzalez-Codova, A.F.; Hernandez-Mendoza, A.; Vallejo-Cordoba, B. Immuno-modulating peptides obtained from milk proteins. Interciencia 2016, 41, 84-91.

21. Ricci, I.; Artacho, R.; Olalla, M. Milk protein peptides with angiotensin i-converting enzyme inhibitory (acei) activity. Crit. Rev. Food Sci. Nutr. 2010, 50, 390-402. [CrossRef]

22. Sienkiewicz-Szłapka, E.; Jarmołowska, B.; Krawczuk, S.; Kostyra, E.; Kostyra, H.; Iwan, M. Contents of agonistic and antagonistic opioid peptides in different cheese varieties. Int. Dairy J. 2009, 19, 258-263. [CrossRef]

23. Purup, S.; Nielsen, S.D.; Le, T.T.; Bertelsen, H.; Sørensen, J.; Larsen, L.B. Wound healing properties of commercial milk hydrolysates in intestinal cells. Int. J. Pept. Res. Ther. 2018. [CrossRef]

24. Nielsen, S.D.; Purup, S.; Larsen, L.B. Effect of casein hydrolysates on intestinal cell migration and their peptide profiles by lc-esi/ms/ms. Foods 2019, 8, 91. [CrossRef] [PubMed]

25. Nielsen, S.D.; Beverly, R.L.; Dallas, D.C. Peptides released from foremilk and hindmilk proteins by breast milk proteases are highly similar. Front. Nutr. 2017, 4, 54. [CrossRef] [PubMed]

26. Nielsen, S.D.; Beverly, R.L.; Qu, Y.Y.; Dallas, D.C. Milk bioactive peptide database: A comprehensive database of milk protein-derived bioactive peptides and novel visualization. Food Chem. 2017, 232, 673-682. [CrossRef] [PubMed]

27. Demers-Mathieu, V.; Nielsen, S.D.; Underwood, M.A.; Borghese, R.; Dallas, D.C. Analysis of milk from mothers who delivered prematurely reveals few changes in proteases and protease inhibitors across gestational age at birth and infant postnatal age. J. Nutr. 2017, 147, 1152-1159. [CrossRef] [PubMed] 
28. Azuma, N.; Nagaune, S.-i.; Ishino, Y.; Mori, H.; Kaminogawa, S.; Yamauchi, K. DNA-synthesis stimulating peptides from human $\beta$-casein. Agr. Biol. Chem. 1989, 53, 2631-2634. [CrossRef]

29. Minervini, F.; Algaron, F.; Rizzello, C.G.; Fox, P.F.; Monnet, V.; Gobbetti, M. Angiotensin i-converting-enzymeinhibitory and antibacterial peptides from lactobacillus helveticus pr4 proteinase-hydrolyzed caseins of milk from six species. Appl. Environ. Microbiol. 2003, 69, 5297-5305. [CrossRef] [PubMed]

30. Nielsen, S.D.; Beverly, R.L.; Dallas, D.C. Milk proteins are predigested within the human mammary gland. J. Mammary Gland Biol. Neoplasia 2017, 22, 251-261. [CrossRef]

31. Dingess, K.A.; van den Toorn, H.W.P.; Mank, M.; Stahl, B.; Heck, A.J.R. Toward an efficient workflow for the analysis of the human milk peptidome. Anal. Bioanal. Chem. 2019, 411, 1351-1363. [CrossRef]

32. Lambers, T.T.; Gloerich, J.; van Hoffen, E.; Alkema, W.; Hondmann, D.H.; van Tol, E.A.F. Clustering analyses in peptidomics revealed that peptide profiles of infant formulae are descriptive. Food Sci. Nutr. 2015, 3, 81-90. [CrossRef] [PubMed]

33. Demers-Mathieu, V.; Qu, Y.; Underwood, M.A.; Dallas, D.C. The preterm infant stomach actively degrades milk proteins with increasing breakdown across digestion time. Acta Paediatr. 2018, 107, 967-974. [CrossRef]

34. Palla, M.R.; Harohalli, S.; Crawford, T.N.; Desai, N. Progression of gastric acid production in preterm neonates: Utilization of in-vitro method. Front Pediatr. 2018, 6, 211. [CrossRef] [PubMed]

35. Gidrewicz, D.A.; Fenton, T.R. A systematic review and meta-analysis of the nutrient content of preterm and term breast milk. BMC Pediatr. 2014, 14, 216. [CrossRef]

36. Mandalari, G.; Adel-Patient, K.; Barkholt, V.; Baro, C.; Bennett, L.; Bublin, M.; Gaier, S.; Graser, G.; Ladics, G.S.; Mierzejewska, D.; et al. In vitro digestibility of $\beta$-casein and $\beta$-lactoglobulin under simulated human gastric and duodenal conditions: A multi-laboratory evaluation. Regul. Toxicol. Pharmacol. 2009, 55, 372-381. [CrossRef] [PubMed]

37. Gass, J.; Vora, H.; Hofmann, A.F.; Gray, G.M.; Khosla, C. Enhancement of dietary protein digestion by conjugated bile acids. Gastroenterology 2007, 133, 16-23. [CrossRef]

38. Giromini, C.; Cheli, F.; Rebucci, R.; Baldi, A. Invited review: Dairy proteins and bioactive peptides: Modeling digestion and the intestinal barrier. J. Dairy Sci. 2019, 102, 929-942. [CrossRef]

39. Jauhiainen, T.; Korpela, R. Milk peptides and blood pressure. J. Nutr. 2007, 137, 825s-829s. [CrossRef]

(C) 2020 by the authors. Licensee MDPI, Basel, Switzerland. This article is an open access article distributed under the terms and conditions of the Creative Commons Attribution (CC BY) license (http://creativecommons.org/licenses/by/4.0/). 